Article

\title{
New Manufacturing Process of Composites Reinforced with ZnO Nanoparticles Recycled from Alkaline Batteries
}

\author{
Isaac Lorero ${ }^{1, *}{ }^{(\mathbb{0}}$, Mónica Campo ${ }^{1}$, Gilberto Del Rosario ${ }^{2}$, Félix Antonio López ${ }^{3}{ }^{(1)}$ and \\ Silvia González Prolongo ${ }^{1, *(\mathbb{D})}$ \\ 1 Materials Science and Engineering Area, Rey Juan Carlos University, C/Tulipán s/n, \\ 28933 Móstoles, Madrid, Spain; monica.campo@urjc.es \\ 2 Laboratory for Electron Microscopy, Centre for Technical Support (CAT), Rey Juan Carlos University, \\ C/Tulipán s/n, 28933 Mostoles, Madrid, Spain; gilberto.delrosario@urjc.es \\ 3 National Centre for Metallurgical Research (CENIM), Spanish National Research Council (CSIC), Avda, \\ Gregorio del Amo, 8, 28040 Madrid, Spain; flopez@cenim.csic.es \\ * Correspondence: isaac.lorero@urjc.es (I.L.); silvia.gonzalez@urjc.es (S.G.P.)
}

Received: 29 June 2020; Accepted: 17 July 2020; Published: 21 July 2020

\begin{abstract}
A new manufacturing method of thermosetting resins reinforced with dense particles is developed in the present work. A rotary mold is used, avoiding the natural sedimentation of particles through applying centrifuge forces. A deep study of the sedimentation phenomenon is carried out in order to evaluate the main experimental parameters which influence the manufacturing of composite. The used reinforcement is zinc oxide $(\mathrm{ZnO})$ obtained by a new recycling method from spent alkaline batteries. In order to compare the benefits, commercial $\mathrm{ZnO}$ nanoparticles are also analyzed. Recycled $\mathrm{ZnO}$ particles enhance the interaction of the epoxy matrix due to their inner moisture, allowing the manufacture of composites with relatively high ceramic content. Moreover, an increment in the glass transition temperature of the epoxy matrix and in the mechanical properties, such as its stiffness and hardness, is achieved.
\end{abstract}

Keywords: nanocomposites; epoxy; zinc oxide; sedimentation; recycled alkaline batteries

\section{Introduction}

The manufacture of new materials with hydrophobic polymer surfaces has attracted increasing attention in recent years. Capabilities like self-cleaning, anti-icing, corrosion inhibition, or hydrothermal ageing resistance can be considered among the properties derived from water and moisture repellent surfaces [1-6]. This behavior depends on several experimental parameters, such as the geometry of the surface, measured by superficial roughness, and the chemistry of materials. Due to its intrinsic characteristics, many thermosets commonly used in the industry, as the epoxy resins for manufacturing composites and coatings, present a hydrophilic nature. One way to enhance the hydrophobicity of these matrix surfaces is the introduction of dispersed ceramic nanoparticles, which increase its roughness. The application of different post-treatments can reduce the surface energy and contribute to create hierarchical micro and nanostructures [7-11]. In addition to providing hydrophobicity, the ceramic nanoreinforcements contribute with other improvements: increase in mechanical properties when there is an effective adhesion with the matrix, increase of thermal stability, enhancement of hardness, and wear resistance among others [5,12-16]. Between the ceramic nanoreinforcements based on the metallic oxides, $\mathrm{ZnO}$ nanoparticles are widely studied because of their varied and exceptional properties for different technological applications, which make this material an appropriate selection to produce multifunctional materials [15,17-21]. One interesting attribute for its use as a reinforcement for resins 
is its high-quality dispersion and low tendency to form large aggregates within the matrix compared to other oxide nanoparticles [4,17]. Also, previous researches found that $\mathrm{ZnO}$ particles may catalyze the epoxy curing reaction, increasing the crosslinking density of the epoxy network [22-24]. Zinc oxide can introduce other advantages, such as the enhancement of antibacterial activity, piezoelectricity, corrosion and UV degradation resistance, increased thermal conductivity, or the capacitance for new structural supercapacitors in comparison with neat resins [17,25-33].

The use of alternative recycling synthesis to recover materials as ceramic oxides opens an interesting opportunity to create composites by more sustainable ways [34]. "Urban mining" is the recovery of metals and ceramics through mechanical and chemical treatments, providing ecological and effective reinforcements. For example, hydrometallurgical routes could generate particles with inherent moisture, being able to enhance the crosslinking density and the interaction with the matrix and thus positively influence thermomechanical composites properties [22,23].

On the other hand, the inherent moisture can also enhance the agglomeration phenomenon of particles, hindering the dispersion. In that way, $\mathrm{ZnO}$ particles, recovered from spent alkaline batteries, have been used in the present research as fillers of composites in order to compare its efficiency regard to commercial nanoparticles $[35,36]$. It is worthy to note that this work seeks new applications for recycled $\mathrm{ZnO}$ from batteries, whose mass storage as waste contributes to environmental and health problems. According to battery sales worldwide, the most used battery type is alkaline batteries $(75 \%)$ due to their having a higher performance than other batteries. Each year, thousands of tons of alkaline batteries must be recycled, thus new use of the obtained recycled materials must be developed.

Looking at the main factors to consider during the manufacturing of these composite materials, the high differences in density between ceramic fillers and polymer resins reveals one of the most critical points. This gap, attached to their high specific areas of fillers, which induces severe problems of aggregation, the relative low viscosity of epoxy monomers and large gel time during the curing process of thermosetting resins could lead to pauperize the reinforcement dispersions. This could cause the particles sedimentation to the bottom of composite, avoiding the potential improvements in material properties due to the heterogeneity of samples. Higher particle sizes also reveal as a decisive factor in these sedimentation phenomenon [37]. One way to favor the maintenance of ceramic filler dispersions within the matrix for the curing process is the functionalization of the particles by chemical treatments before mixing with the resin. Repulsive forces between functionalized particles and positive interactions with the polymer matrix prevent their agglomeration and sedimentation. However, these treatments imply some limitations for future industrial applications due to the use of unhealthy reagents and the increase of manufacturing times. Our current proposal consists of the neutralization of downfall movements of fillers into thermosetting resin through the removal of the gravity effect by applying mechanical movements. This solution provides easier and faster manufacturing routes to obtain well dispersed and effective composites.

In the present research, a new manufacturing technique is optimized, creating one method able to leave out the pre-treatment of a particle's functionalization through using a rotary mold during the curing cycle of composite. Thanks to the rotational movement, the sedimentation is avoided, and the reinforcement distribution achieved during the previous sonication dispersion is maintained, creating homogeneous composites with enhanced thermo-mechanical properties and hardness.

As mentioned above, the main goal is to develop a new method to manufacture epoxy composites with recycled $\mathrm{ZnO}$ particles from spent alkaline batteries are used as fillers in comparison with commercial nanoparticles. The battery recycling and the reuse of obtained $\mathrm{ZnO}$ particles have important environmental and economic benefits. 


\section{Experimental}

\subsection{Materials}

Polymer matrix used in the present work was a two-component epoxy resin based on bisphenol A (Araldite LY 556) mixed with aromatic amine hardener (XB 3473) in a weight ratio of 100:23. Both components were purchase from Huntsman (Woodlands, TX, USA). In order to analyze the influence of ceramic filler characteristics on the epoxy properties, two different zinc oxides were selected: commercial nanoparticles with $>98 \%$ purity supplied by Merck (Darmstadt, Germany) and alternative particles recovered from spent alkaline batteries [35]. The synthesis of this second type of zinc oxide consists on a three stages process:

1. Leaching of batteries black mass: black mass was leached by adding $1.72 \mathrm{~mol} / \mathrm{L}$ of $\left(\mathrm{NH}_{4}\right)_{2} \mathrm{CO}_{3}$ and $0.5 \mathrm{~mol} / \mathrm{L}$ of $\mathrm{NH}_{3}$. Black mass pulp concentration was settled at $100 \mathrm{~g} / \mathrm{L}$ and the solution was agitated at $1800 \mathrm{rpm}$ under ambient conditions for $1 \mathrm{~h}$. The after-treatment suspension obtained was filtered under vacuum and leachate was kept for further processing.

2. Leachate evaporation under vacuum ( $34 \mathrm{mbar}$ ) and drying of the solid precursor gotten in an oven at $80^{\circ} \mathrm{C}$ for $6 \mathrm{~h}$.

3. Calcination of the post-evaporation solid precursor at $800^{\circ} \mathrm{C}$ for $5 \mathrm{~h}$ to obtain the $\mathrm{ZnO}$.

Finally, the manufactured composites were treated with successive chemical immersions to give them hydrophobicity. For that, sulfuric acid, ethanol, glacial acetic acid, and stearic acid are used as chemical solvents. All these reagents were supplied by Merck. It is worthy to note that all components were used as received and none of the particles were functionalized or treated before the composites manufacturing.

\subsection{Composites Manufacturing}

Neat epoxy resin, without filler, was manufactured and taken as reference of the research. On the other hand, epoxy composites were manufactured by adding different concentrations of commercial and recycled $\mathrm{ZnO}(2,6$, and $10 \mathrm{wt} \%)$. Finally, due to the obtained results, another sample with a $30 \mathrm{wt} \%$ of $\mathrm{ZnO}$ was used to analyze the influence of higher loads.

To create the composites, the epoxy resin was heated up to $50{ }^{\circ} \mathrm{C}$ to reduce its viscosity and then the $\mathrm{ZnO}$ particles were added and mixed mechanically. To achieve a homogeneous distribution, the particles were dispersed afterwards into the epoxy matrix by sonication with a cycle of $50 \mathrm{~Hz}$ and $50 \%$ of amplitude during $1 \mathrm{~h}$. This was done by using a $7 \mathrm{~mm}$ diameter probe sonicator. To control the temperature during sonication and avoid overheating capable of triggering epoxy homopolymerization, cold water baths were placed around the epoxy-ZnO mixtures. Afterwards, the dispersion was degassed $15 \mathrm{~min}$ at $80{ }^{\circ} \mathrm{C}$. Then, the hardener was added in a stoichiometric ratio and finally the non-cured mixture was placed in a mold for curing at $140{ }^{\circ} \mathrm{C}$ for $8 \mathrm{~h}$.

Composites were manufactured by two different molding methodologies. First, the materials were putted into an open mold, which remains static in the oven during the curing cycle. Due to the undesirable sedimentation of fillers, a rotary molding system were probed to avoid this phenomenon (Figure 1). In these cases, composites were introduced into a closed mold, which was screwed to a rotation shaft placed along the oven. The rotation shaft was actuated by an external electric engine to move the mold at $11 \mathrm{rpm}$ in order to prevent the downward movement of ceramic particles. To avoid the air occlusion inside the rotary mold and the consequent porosity in cured composites, the mold must be slightly overfilled before closing and starting the curing cycle. 


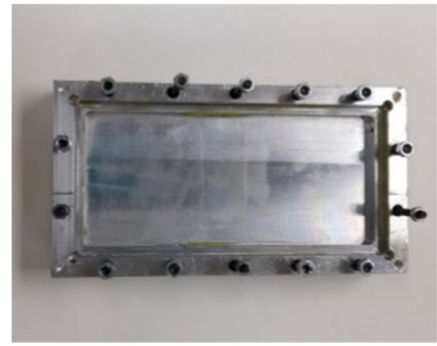

(a)

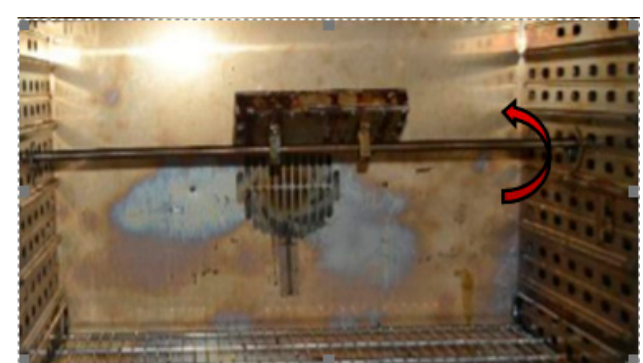

(b)

Figure 1. Rotary mold used for composites manufacturing. (a) View of the disassembled rotary mold; (b) Rotary mold working inside the oven.

\subsection{Characterization}

The morphology of the particles used as reinforcements were characterized by field emission scanning electron microscopy (FEG-SEM, Nova Nano SEM230 model, FEI, Hillsboro, OR, USA).

$\mathrm{ZnO}$ particles were analyzed by Fourier transform infrared spectroscopy (FTIR), using a Varian 670 FTIR spectrometer (Varian Inc., Palo Alto, CA, USA) (spectral range $4000-400 \mathrm{~cm}^{-1}$, spectral resolution of $4 \mathrm{~cm}^{-1}$ ) in transmittance mode. This analysis was performed using $\mathrm{KBr}$ pellets with $1 \mathrm{wt} \%$ of $\mathrm{ZnO}$. Epoxy-ZnO composites were also analyzed by Attenuated total reflectance-Fourier transform infrared spectroscopy (ATR-FTIR) (Varian Inc., Palo Alto, CA, USA) with Nicolet (Termo Fischer Scientific Inc., Waltham, MA, USA) ATR accesory (spectral range $3800-700 \mathrm{~cm}^{-1}$ ). The chemical composition of recycled $\mathrm{ZnO}$ was also analyzed by $\mathrm{X}$-ray fluorescence $(\mathrm{XRF})$ using a PANalytical Acios wavelength dispersive spectrometer ( $4 \mathrm{~kW}$ ) (Malvern, Worcestershire, United Kingdom).

The dispersions of the zinc oxide in epoxy monomer were evaluated with a reflected light microscope (Transmission optical microscope, TOM, Leyca Microsystem M205 C, Weltzar Germany). These images were digitally analyzed to characterize the distribution and size of particles and aggregates. Later, the final dispersion on cured composites was analyzed by scanning electron microscopy (SEM, Hitachi S3400N, Tokyo, Japan).

Thermomechanical properties of neat resin and composites were measured by dynamical thermomechanical analysis (DTMA) (New Castle, DE, USA) with a Q800 TA Instruments. Tests were made in single cantilever mode with an amplitude of $1 \%$ regard to samples thickness and a frequency of $1 \mathrm{~Hz}$. Thermomechanical data were collected in a temperature range from $30{ }^{\circ} \mathrm{C}$ to $230{ }^{\circ} \mathrm{C}$ with a heating rate of $2{ }^{\circ} \mathrm{C} / \mathrm{min}$.

Composites Vickers micro hardness were measured by applying $980.7 \mathrm{mN}$ loads with a Shimadzu HMV-2T indentation tester.

\section{Results and Discussion}

\subsection{Characterization of Reinforcements}

Both zinc oxides used as reinforcements, recycled and commercial ones, were characterized by field emission scanning electron microscopy (FEG-SEM) images. Their morphologies are shown at Figure 2. Commercial $\mathrm{ZnO}$ nanoparticles show varied geometries with predominant elongated shapes up to $500 \mathrm{~nm}$. On the other hand, recycled particles have nanoplatelet morphologies with an average thickness of $35 \mathrm{~nm}$. These platelets are grouped, forming desert roses with diameters around $2.5 \mu \mathrm{m}$. It is worthy to note that the recycled particles, whose synthesis has been previously published [35], show a homogenous geometry, without any other residual components. This enhances its use as filler. 


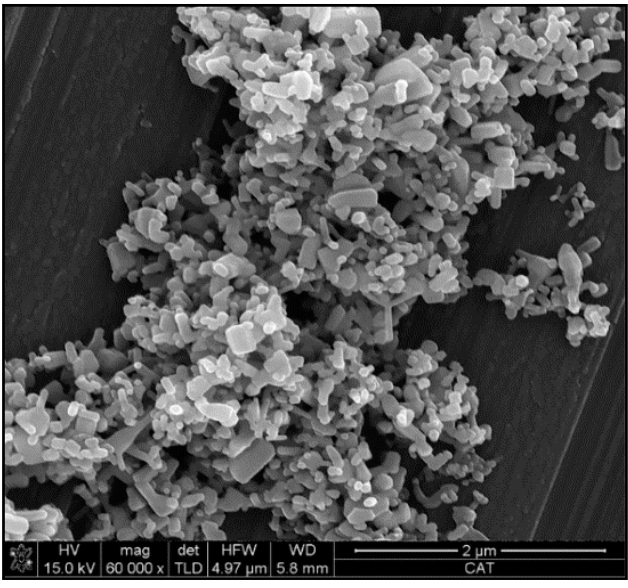

(a)

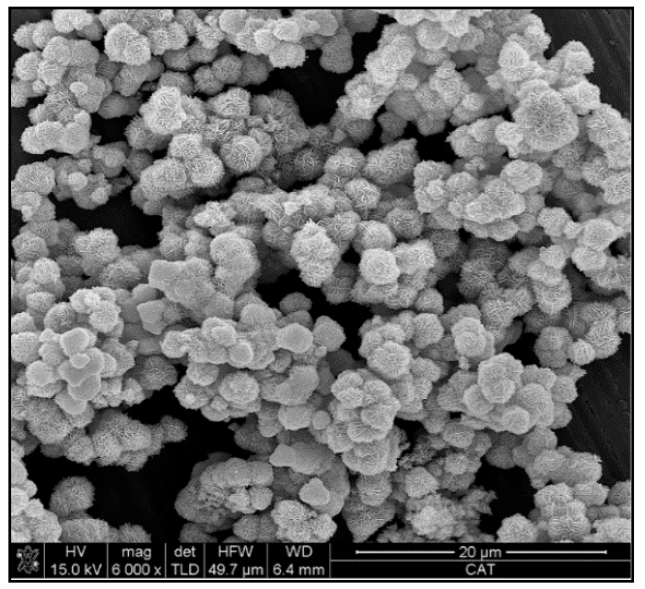

(c)

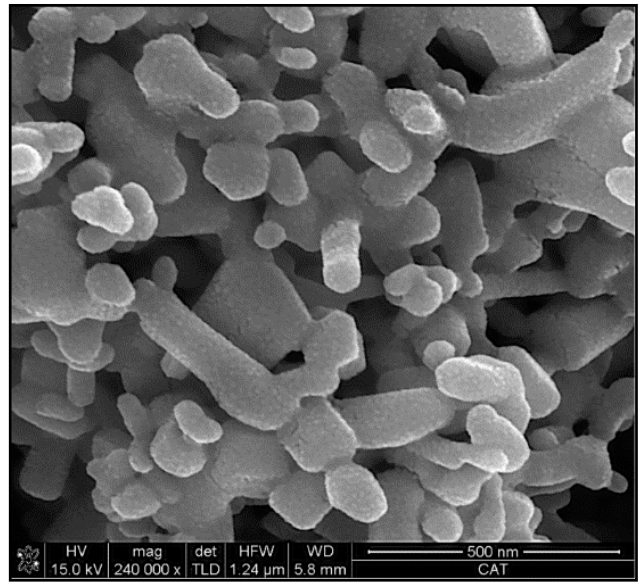

(b)

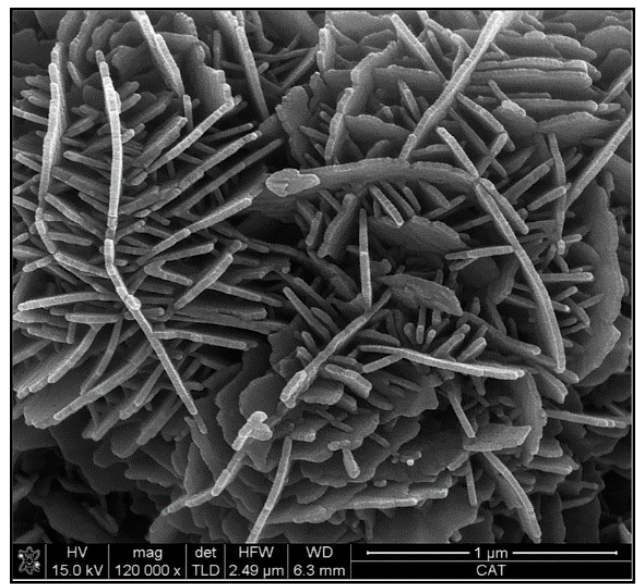

(d)

Figure 2. FEG-SEM images of commercial $(\mathbf{a}, \mathbf{b})$ and recycled zinc oxide $(\mathbf{c}, \mathbf{d})$. Write square $(\mathbf{a}, \mathbf{c})$ indicates the magnified area $(\mathbf{b}, \mathbf{c})$.

Figure 3 shows FTIR spectra of both zinc oxides. Compared to commercial zinc oxide, a stronger signal can be observed in recycled around 3430 and $1640 \mathrm{~cm}^{-1}$ due to the presence of bonded water. This is associated to the inherent intrinsic moisture of particles obtained by hydrothermal recycling manufacture. FTIR also confirms that recycled $\mathrm{ZnO}$ particles have a high purity, without identifying notable rests of other chemicals from recycling of batteries, showing, in addition to the $\mathrm{O}-\mathrm{H}$ bands, a unique characteristic peak at $420 \mathrm{~cm}^{-1}$ associated with the $\mathrm{Zn}-\mathrm{O}$ bond. In that way, Table 1 notes the chemical composition of recycled $\mathrm{ZnO}$ powder determined through XRF in previous research: $\mathrm{ZnO}$ contents are above $92 \mathrm{wt} \%$. and only significant quantities of $\mathrm{K}_{2} \mathrm{O}$ and $\mathrm{P}_{2} \mathrm{O}_{5}$ were founded [35].

Table 1. Recycled $\mathrm{ZnO}$ chemical composition.

\begin{tabular}{ccccccccccccc}
\hline $\mathrm{MgO}$ & $\mathrm{Al}_{2} \mathrm{O}_{3}$ & $\mathrm{SiO}_{2}$ & $\mathrm{P}_{2} \mathrm{O}_{5}$ & $\mathrm{Cl}$ & $\mathrm{K}_{2} \mathrm{O}$ & $\mathrm{CaO}$ & $\mathrm{TiO}_{2}$ & $\mathrm{MnO}$ & $\mathrm{Fe}_{2} \mathrm{O}_{3}$ & $\mathrm{NiO}$ & $\mathrm{CuO}$ & $\mathrm{ZnO}$ \\
\hline 0.4 & 0.09 & 0.16 & 1.48 & 0.03 & 4.20 & 0.34 & 0.03 & 0.02 & 0.10 & 0.11 & 0.17 & 92.73 \\
\hline
\end{tabular}




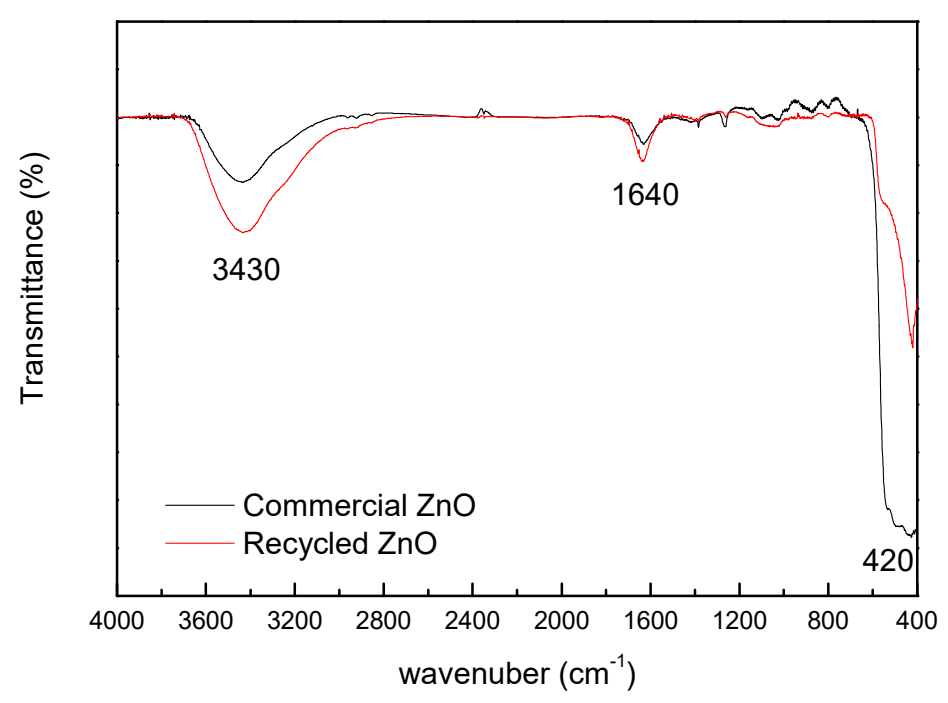

Figure 3. Commercial and recycled zinc oxides FITR spectra.

\subsection{Sedimentation Analysis and Desing for Rotary Moulding}

\subsubsection{Analysis of Particles Sedimentation}

The main source of sedimentation phenomenon is a high difference between the density of polymer matrix and ceramic reinforcements. The sedimentation occurs when mixtures are poured into molds, without forced agitation and external movements for curing, and the viscosity of non-cured resin is considerably low, and its gel times is quite long. Reynolds numbers within polymer matrix are very reduced and flows can be defined by laminar regimes. In these cases, sedimentation of particles can be modelized by the Stokes law [38]:

$$
v_{s}=\frac{2}{9} \frac{r^{2} g\left(\rho_{p}-\rho_{r}\right)}{\eta}
$$

where $v_{S}$ is the sedimentation speed, $r$ is the particles equivalent ratio, $\rho_{p}$ and $\rho_{r}$ are the densities of the particles and resin, respectively and $\eta$ is the viscosity of non-cured resin. Particles agglomeration, after dispersion treatments, is favored in low viscosities mixtures. This behavior increases sharply the reinforcement tendency to sedimentation because the terminal speed maintains an exponential relationship with particle or aggregate sizes. Moreover, the sedimentation speed of each particle or aggregate depends on the gel time of the resin, which is the time to reach a network in gel state.

In this moment, the sedimentation phenomenon stops. Naturally, the sedimentation is also affected by the particle's downfall across the thicknesses of the composites:

$$
d_{s}=v_{s} \cdot t_{g e l}
$$

where $v_{S}$ is the sedimentation speed, $d_{S}$ is the thickness of the composite and $t_{\text {gel }}$ is the gelation time of resin.

The sedimentation of zinc oxides, or any other particle-shaped reinforcement, can be studied through Equations (1) and (2) and trough the characterization of the particle's dispersions within the matrices. The polymer matrix used, Araldite LY556, is an aeronautical degree resin with very low viscosity at high temperatures. Its rheological behavior was characterized in previous researches, founding that viscosity descends below $0.1 \mathrm{~Pa} \cdot \mathrm{s}$, when temperature increases up to curing set point [39]. XB 3474, as usual in amine hardeners, also presents quite lower viscosities and contributes to further reduce these values. To consider the reinforcement effect, other studies analyzed the increase of the epoxy viscosity with the addition of $\mathrm{ZnO}$ particles. In general, it does not grow notably until the weight percentage of 
reinforcement approaches to $30 \%$. At these concentrations, viscosity increases up to a hundred per cent compared with the neat resin. Beyond this particle concentrations, the viscosity increases exponentially, and the composite begins to be excessively difficult to manufacture by molding [40].

Therefore, the sedimentation phenomenon can be modelized by calculating terminal speed and sedimentation distances as functions of reinforcement equivalent ratios and taking into account the following parameters:

$$
\rho_{p}=5610 \frac{\mathrm{kg}}{\mathrm{m}^{3}}, \rho_{r}=1120 \frac{\mathrm{kg}}{\mathrm{m}^{3}}, \eta_{\min }=0.05 \mathrm{~Pa} \cdot \mathrm{s}, \eta_{\max }=0.1 \mathrm{~Pa} \cdot \mathrm{s}, t_{\mathrm{gel}}=35 \mathrm{~min}
$$

Viscosities values of the mixtures of resin, hardener and particles are settled as medium rates before gelation time. On the other hand, $t_{g e l}$ of composites is settled according to experimental measurements. Looking to the referenced bibliography [39], the viscosities values for composites reinforced up to $20 \mathrm{wt} \% \mathrm{ZnO}$ contents are expected to be closer to the minimum rate and nearest to the top for composites reinforced with contents at $30 \mathrm{wt} \%$. If powder loads rise above this last concentration, it would be expected that the exponential growth of viscosity implies a reduction of sedimentation phenomena to neglectable values.

At this point, it is worth mentioning that some extended modifications of Equation (1) were purposed by other authors to consider the effect of parameters like volume fraction of powders and dispersion effectiveness within fluids [41,42]. However, it was considered more convenient to define a working region in Figure 4 marked off by maximum and minimum sedimentation curves delimited by lowest and highest viscosities reachable for manufacturable LY556-ZnO dispersions.

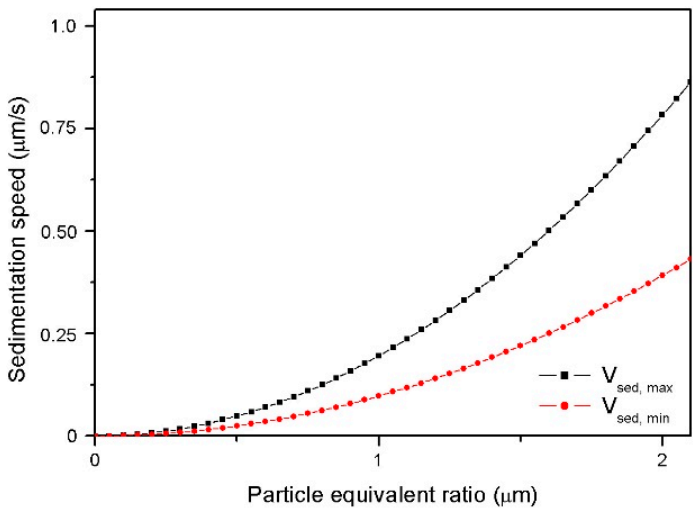

(a)

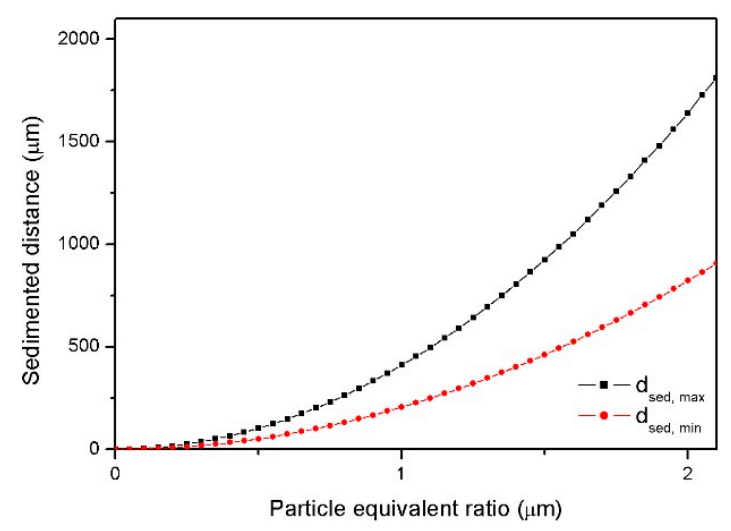

(b)

Figure 4. Theoretical sedimentation speed of $\mathrm{ZnO}$ within LY 556 (a) and sedimented distance before gelation (b).

The sedimentation speeds and the particles downfalls are shown in Figure 4, confirming that the sedimentation strongly depends on the size of particles. Thus, an experimental analysis of particles dispersion was made. $\mathrm{ZnO}$ particles were dispersed in the epoxy monomer by sonication for $1 \mathrm{~h}$. The reinforced matrices were observed to characterize the sonication effectivity and to analyze the size distribution of ceramic particles and agglomerates. Figure $5 \mathrm{a}, \mathrm{b}$ exhibits the dispersion of non-cured mixtures reinforced with both zinc oxide particles at $6 \mathrm{wt} \%$ content. The sonication effectivity for commercial particles into non-cured resin is quite high, so large aggregates are removed, and particles sizes are considered with equivalent ratios smaller than $1 \mu \mathrm{m}$, the detection limit of transmission optical microscopy. On the other hand, the dispersions of recycled zinc oxides can be properly characterized by TOM due to its higher particles size. Further, the sonication cycle used is not so efficient with this reinforcement and it can be seen a certain presence of aggregates. Figure $5 b$ shows a histogram with the particles and agglomerates sizes distribution observed. These clear differences of behavior are explained by the different geometry and composition of both studied ceramic particles. 

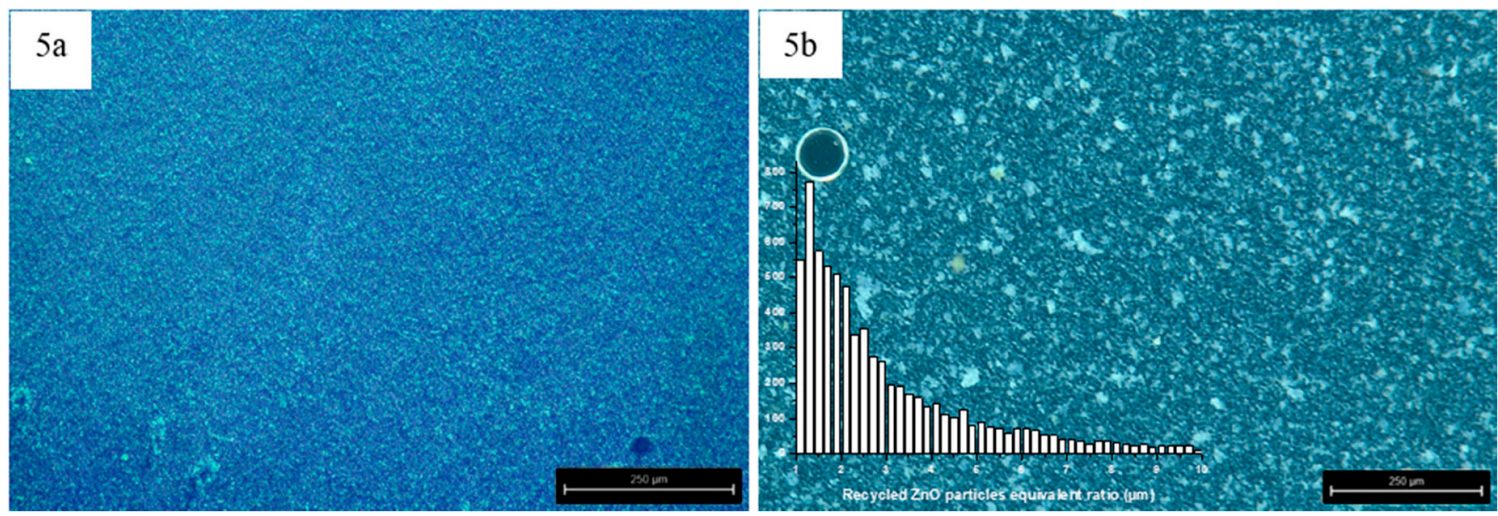

Figure 5. TOM images of the dispersion of non-cured mixtures with $6 \mathrm{wt} \%$ commercial $\mathrm{ZnO}(\mathbf{a})$ and recycled $\mathrm{ZnO}$ and histogram with its particles and aggregates size distribution $(\mathbf{b})$.

Although the dimensions of both isolated ceramic fillers, commercial and recycled ones, have nanoscale, the recycled $\mathrm{ZnO}$ particles has an important tendency to form micro-scale agglomerations (Figure 2d) due to their inherent moisture (Figure 3). This means that the achieved dispersions are suitable and the best available. The modification of experimental dispersion parameters does not imply better dispersion of recycled particles.

Figure 6 shows SEM images of the cross-section of manufactured composites. Due to the different real size of ceramic particles, the composites reinforced with recycled $\mathrm{ZnO}$ suffer more severe sedimentation (Figure 6b,d) compared to composites filled with commercial $\mathrm{ZnO}$ (Figure 6a). Figure 6d,e shows a comparison among theoretical sedimentation (left, calculated by Equations (1) and (2)) and the real particles distribution observed with SEM (right) of epoxy composite reinforced with recycled $\mathrm{ZnO}$. Therefore, it is confirmed that the presented sedimentation model (Figure 4) can rightly determine the generation of a sediment layer that accumulates more than a half of the total reinforcement added to the matrix is expected for recycled $\mathrm{ZnO}$, which is confirmed by SEM.

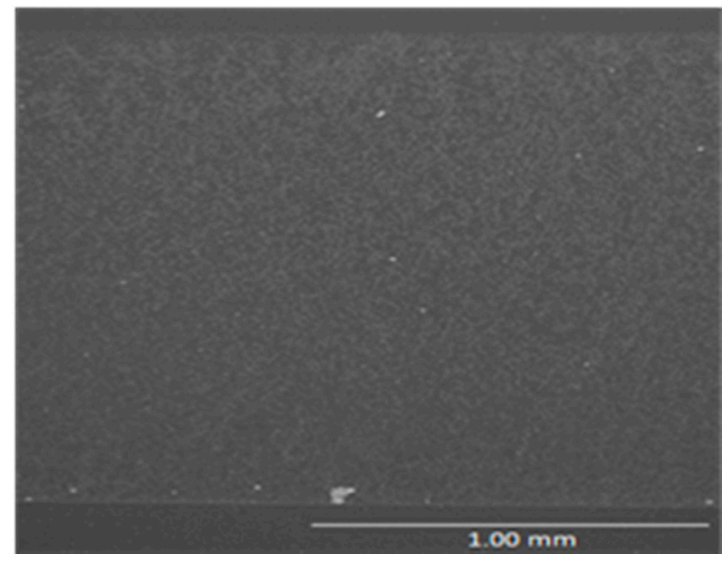

(a)

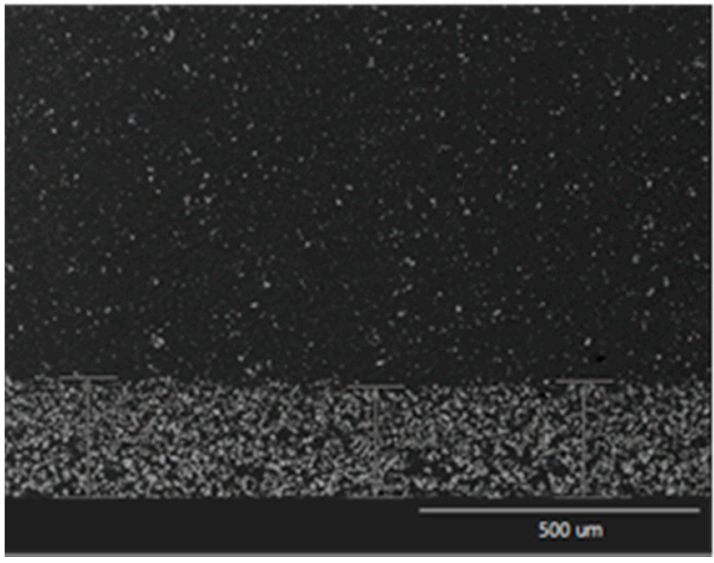

(b)

Figure 6. Cont. 


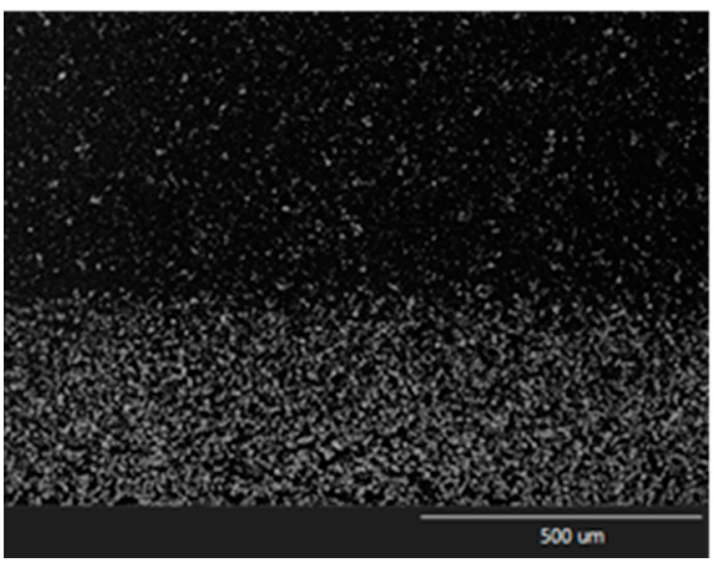

(c)

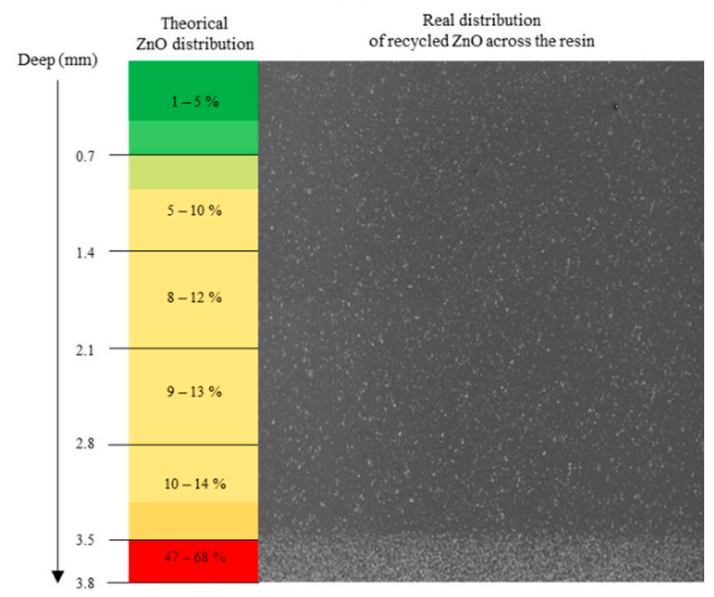

(e)

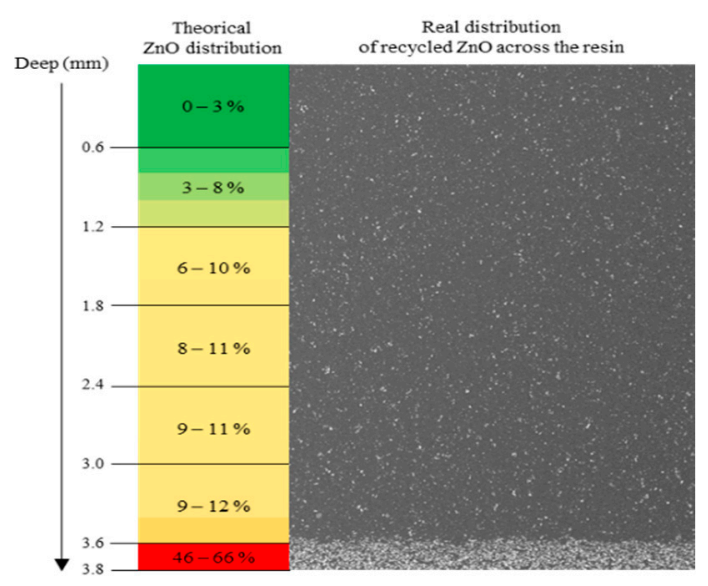

(d)

Figure 6. SEM images of cross-section of cured composites reinforced with 6 wt $\%$ of commercial $\mathrm{ZnO}$ (a) and $6 \mathrm{wt} \%$ (b) and $10 \mathrm{wt} \%$ (c) of recycled $\mathrm{ZnO}$. A comparison among theoretical sedimentation (left) and the real particles distribution observed with SEM at high magnification (right) of epoxy composite reinforced $6 \mathrm{wt} \%(\mathbf{d})$ and $10 \mathrm{wt} \%(\mathbf{e})$ of recycled $\mathrm{ZnO}$.

Comparing both composites manufactured with different contents of recycled $\mathrm{ZnO}$ particles (Figure $6 \mathrm{~b}, \mathrm{c}$ ), the thickness of sedimented layer grows in proportion to the added $\mathrm{ZnO}$ percentage. However, in both cases, the recycled zinc oxide mass fraction in the sediment layers are near to $70 \%$. This value was determined by image analysis. Therefore, the quantity of particles added into the resin has no noticeable influence on the percentage accumulated in the sediment layer, only affecting its thickness. This saturation of particles in the down sediment layer can be explained by an abrupt local increase of viscosity at the bottom, due to the sedimentation phenomenon, leading to create a resistance against the downfall of the reinforcement. Consequently, a uniform sedimented layer is developed, which contains a constant value near to $70 \mathrm{wt} \%$ of $\mathrm{ZnO}$ and whose thickness depends on the $\mathrm{ZnO}$ content added into the epoxy matrix.

\subsubsection{Design of Rotary Molding}

The experimental results shown confirm that the sedimentation of the studied composites, considering the low viscosity and long gel time of epoxy matrix, strongly depends on the size of particles and agglomerations. In fact, the better dispersion achieved for composites reinforced with commercial $\mathrm{ZnO}$ avoids the sedimentation. However, the tendency to agglomerate of recycled ceramic particles, which implies an important increase of their effective filler size, causes an important sedimentation phenomenon. According to Equation (1), the unique mode to avoid the sedimentation 
phenomena is to remove the gravity effect. In that way, the use of a closed mold that rotates around a concentric axis throughout the curing treatment, at least up to gel time, is analyzed. This concentric rotation prevents the downfall of particles by forcing them to move in conjunction with the mold.

However, this rotary motion induces centrifugal acceleration to the particles that should be considered to ensure that dispersions remain homogeneous until the resin gelation.

$$
\begin{gathered}
v_{c}=\frac{2}{9} \frac{r^{2} a_{c}\left(\rho_{p}-\rho_{r}\right)}{\eta} \\
a_{c}=\omega^{2} R
\end{gathered}
$$

where $a_{c}$ is the centrifugal acceleration, $\omega$ the angular speed of the mould an $R$ the distance between mould and rotation axis.

As shown in Equation (3), the centrifugal speed of particles keeps some similarity with the sedimentation speed Equation (1), changing the action of the gravity by the centrifugal acceleration. Therefore, turning speeds and distances between mold and rotation axis must be reduced to avoid particles movements and maintain the dispersion homogeneity. In the present research, the rotation speed of the mold is fixed at $11 \mathrm{rpm}$ and the distance of the mold with the rotation axis is $10 \mathrm{~cm}$. These experimental parameters generate accelerations near to $0.13 \mathrm{~m} / \mathrm{s}^{2}$ which induce practically negligible displacements to the $\mathrm{ZnO}$ particles during the curing treatment. Figure 7 shows SEM images of a cured composite reinforced with the highest studied content of recycled $\mathrm{ZnO}$ manufactured by rotatory molding. The particles distribution is totally homogenous, avoiding the sedimentation phenomenon.

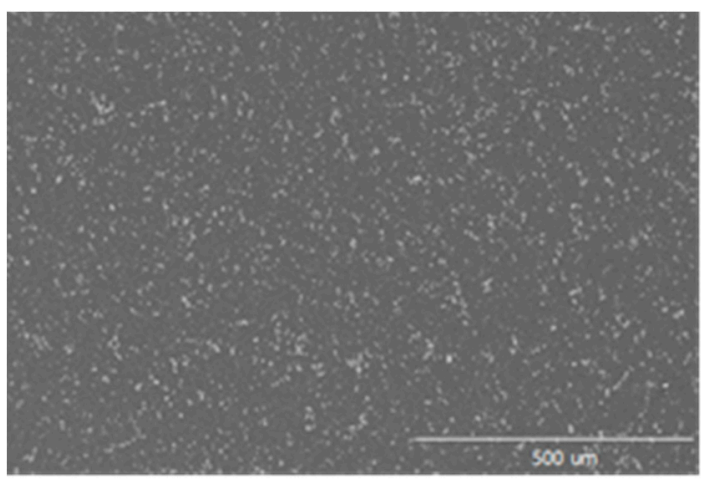

(a)

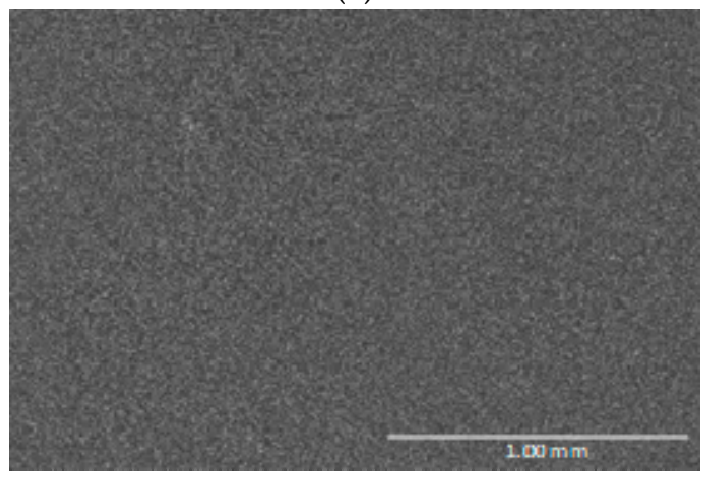

(c)

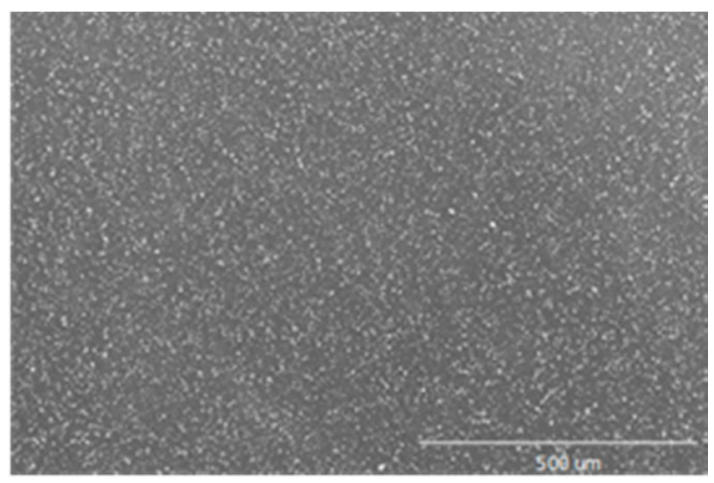

(b)

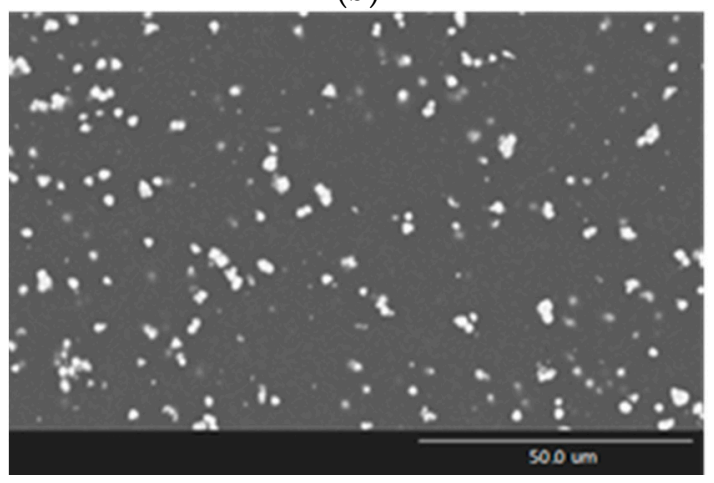

(d)

Figure 7. SEM images of cross-section of cured composites reinforced with 6 (a), 10 (b) and 30 wt \% (c) recycled $\mathrm{ZnO}$ manufactured by rotary molding. Amplified details are observed at high magnification (d). 
Compared with composites manufactured by static molding (Figure 6), this alternative method avoids completely the sedimentation and creates homogeneous materials with enhanced matrix-reinforcement interactions. As high magnification (Figure $7 \mathrm{~b}$ ), it is possible to observe the isolated particles, whose size is close to $1-3 \mu \mathrm{m}$, similar to initial dispersion achieved by sonication (histogram in Figure $5 \mathrm{~b}$ ). Moreover, a new composite reinforced with $30 \mathrm{wt} \%$ of $\mathrm{ZnO}$ was manufactured by the designed rotatory molding, confirming homogenous distribution of the ceramic fillers without high agglomerations or sedimentation (Figure 7c). These improved composites could be adequate for insulation applications, with enhanced hydrothermal ageing resistance thanks to the homogeneous presence of $\mathrm{ZnO}$ across the matrix. A homogenous ceramic dispersion on the nanocomposites also enhances their wear properties, making them interesting protective coatings with high chemical and wear resistance.

In summary, to avoid the sedimentation is possible to modify the experimental parameters of materials, such as a reduction of particle size, an increase of resin viscosity or a decrease of gel time. However, for determined materials, the unique mode to avoid it is to modify the molding process, changing the gravity by rotatory forces. In fact, the authors have designed a new method of molding process of composites which allows to fully eliminate the sedimentation phenomena. This method is very suitable to manufacture epoxy resins with recycled $\mathrm{ZnO}$ particles from alkaline batteries, giving a new use and application and avoiding the environmental problems of their waste storage.

\subsection{Chracterization of Composites}

\subsubsection{FTIR Analysis}

The effect of $\mathrm{ZnO}$ on epoxy matrix is analyzed through ATR technique. FTIR spectra of epoxy resin and composites do not show significant absorption peaks at $915 \mathrm{~cm}^{-1}$ in any sample, indicating that the cure cycles are well designed, and not important amounts of unreacted epoxy rings remain. $\mathrm{ZnO}$ addition does not eliminate characteristic peaks of the matrix spectrum but provokes shifts and changes on the intensities. Similar tendency was observed by Mostafaei et al. [43] and Ammar et al. [4] in epoxy-PANI and epoxy-PMDS composites reinforced until $8 \mathrm{wt} \% \mathrm{ZnO}$. In the composites made through rotary molding in this research, shifts are clearly observed at $1034-1028 \mathrm{~cm}^{-1}, 1234-1229 \mathrm{~cm}^{-1}$ and $3396-3383 \mathrm{~cm}^{-1}$ peaks. Additions of $\mathrm{ZnO}$ up to $6 \mathrm{wt} \%$ displace the peaks to minor wavenumbers, but when the contents rise to 10 and $30 \mathrm{wt} \%$, the trend reverses and peaks wavenumber become closer to the net resin values.

Attenuation on $-\mathrm{OH}$ bands caused by $\mathrm{ZnO}$ are significant. Ghule et al. [44] and Ammar et al. [4] reported this phenomenon and argued that sonication favors the interaction between hydroxyl functional groups and $\mathrm{ZnO}$ particles. In that way, the bands tend to disappear with the increase of the $\mathrm{ZnO}$ content. This effect is deeper in recycled $\mathrm{ZnO}$ composites, which indicates that sonication cycles are well realized, and rotary molding keeps a fine distribution that helps to enhance the interaction between matrix and reinforcement. At $30 \mathrm{wt} \%$ content, the manufacturing of recycled $\mathrm{ZnO}$ composite continues achieving this distribution without the formation of aggregates, as seen in Figure 8, and the -OH band disappear almost completely. However, in the case of $30 \mathrm{wt} \%$ commercial $\mathrm{ZnO}$ composite, the spectrum shows a notable increase on this peak. This opposite behavior can be explained by the excessive viscosity of the mixture, due to the greater particles surface area and high load, which may hinder the sonication effectivity. 


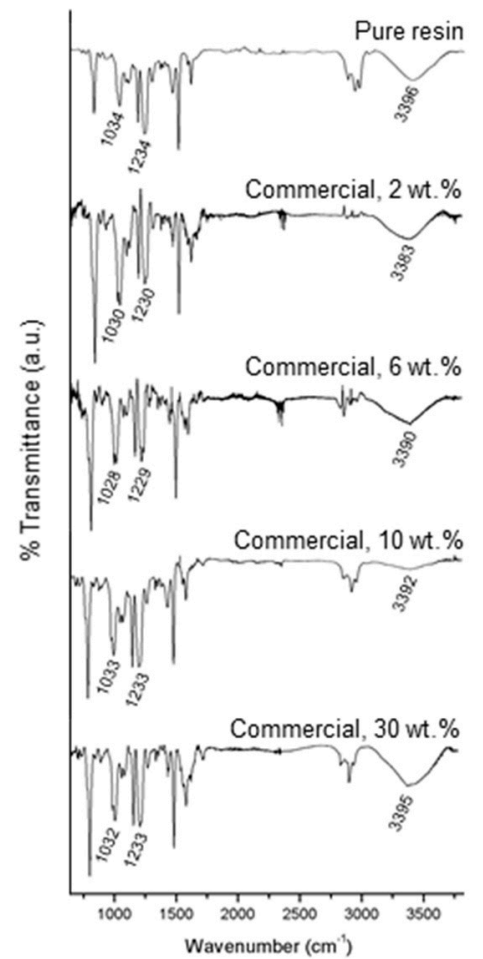

(a)

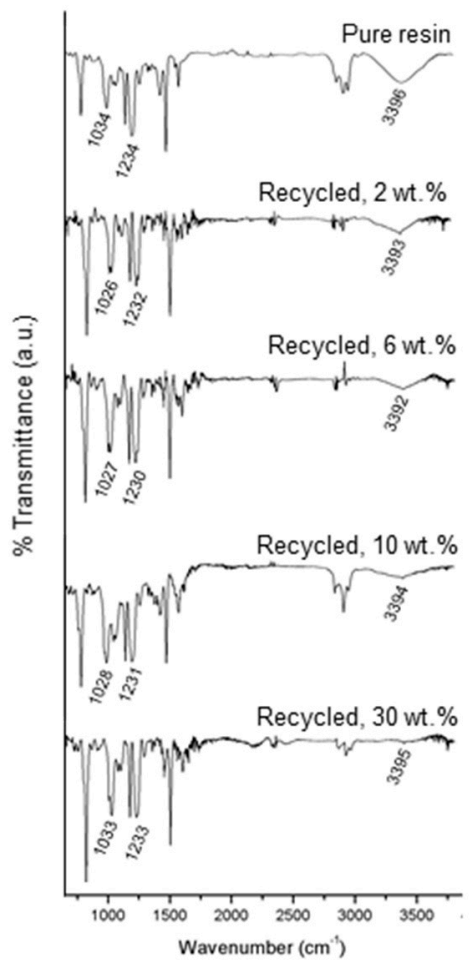

(b)

Figure 8. FTIR spectra of epoxy resin, commercial $\mathrm{ZnO}$ reinforced composites (a) and recycled $\mathrm{ZnO}$ reinforced composites (b).

\subsubsection{Thermo-Mechanical Behavior}

Once the manufacture of epoxy composites doped with recycled and commercial $\mathrm{ZnO}$ particles has been optimized using the rotary molding, their mechanical and thermal properties has been analyzed. DMTA analysis was used to study the thermo-mechanical properties of composites. Figure 9 shows the average values for the storage modulus at room temperature, which are associated to the stiffness, and glass transition temperature $\left(T_{\mathrm{g}}\right)$, whose value indicates the maximum operating temperature, of manufactured composites as a function of $\mathrm{ZnO}$ content.

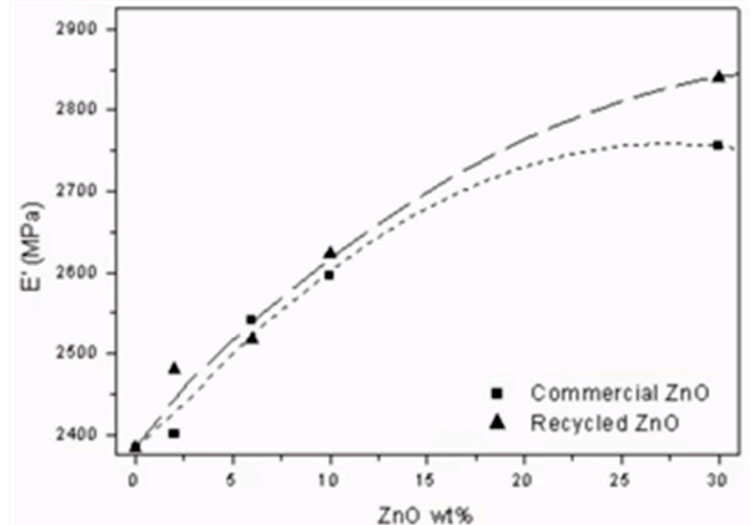

(a)

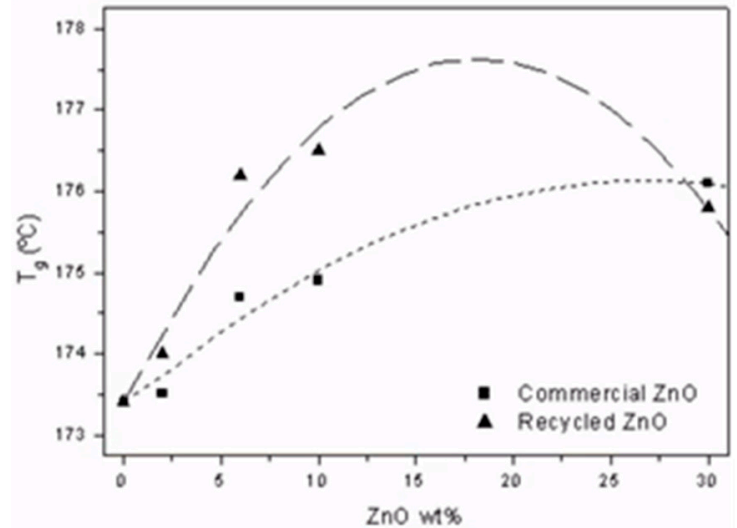

(b)

Figure 9. Storage modulus at $30^{\circ} \mathrm{C}$ (a) and glass transition temperature (b) of $\mathrm{ZnO} /$ epoxy composites. 
As expected, the addition of $\mathrm{ZnO}$ particles achieve increases on glass transition temperatures of composites due to the steric hindrance of ceramic particles on chain segments movements and its capability to catalyze the curing reaction through acid-base interactions with hardener amine groups. Moreover, the inner moisture present in recycled zinc oxide structure seems to enhance the interaction with the polymer matrix compared with commercial $\mathrm{ZnO}$ and brings on its thermal stability with higher values of $T_{\mathrm{g}}[22,23]$. This effect takes special relevance in medium filler loads. As the addition of reinforcement rises to greater values, the full occupation of the free volume of thermosetting matrix limits the enhancement and then the glass transition temperature of $\mathrm{ZnO}$-epoxy composites tends to decrease [45]. Similar behavior at lower particle loads for epoxy/ZnO nanocomposites was observed by Zabihi et al [22]. Recently, Ponnamma et al. [13] revised the influence of $\mathrm{ZnO}$ particles in the glass transition of different polymers. They confirmed that $T_{\mathrm{g}}$ of matrix and crosslinking could decrease due to imperfect dispersions or aggregate formations, even at contents under $2 \mathrm{wt} \%$ [4].

In addition to SEM images shown in Figure 7 and FTIR analysis, the thermomechanical properties obtained by DMTA analysis confirm the high-quality reinforcement dispersions achieved by curing with rotational molding: the addition of $\mathrm{ZnO}$ still improving the epoxy properties with loads closer to $10 \mathrm{wt} \%$.

The storage modulus notably increases with $\mathrm{ZnO}$ percentage for both studied particles. It is worthy to note that, despite of the lower crosslinking degree of their matrix the composites reinforced with commercial $\mathrm{ZnO}$ nanoparticles, they achieve similar stiffness than the epoxy resins doped with recycled ones, especially at medium loads. This effect could be explained by the real nano-scaled size of commercial nanoparticles, which implies a higher surface area, inducing higher interaction areas with the polymer matrix.

\subsubsection{Microhardness}

One of the objectives to add ceramic particles into thermosetting resins is the enhancement of their hardness. Microhardness of the manufactured composites are noted in Table 2. Vickers microhardness of the used neat aeronautical resin is close to 22. The addition of $\mathrm{ZnO}$ particles induces a light increment of hardness without, however, being clearly influenced by the different geometry of ceramic particles [15]. The reason for this is that the composite surface remains unchanged, as is confirmed by SEM images of cross-section. There is an outer micro-scale layer of epoxy resin, which is tested during the hardness test. Nevertheless, at the highest recycled $\mathrm{ZnO}$ content ( $30 \mathrm{wt} \%$ ), the hardness is enhanced by up to $80 \%$. This result implies that ceramic particles appear massively on the surface of the epoxy composites when high contents are added.

Table 2. Microhardness values of neat epoxy and epoxy-ZnO composites.

\begin{tabular}{cccccc}
\hline & $\mathbf{0 w t} \%$ & $\mathbf{2} \mathbf{w t} \%$ & $\mathbf{6} \mathbf{w t} \%$ & $\mathbf{1 0} \mathbf{w t} \%$ & $\mathbf{3 0} \mathbf{w t} \mathbf{~}$ \\
\hline Recycled ZnO & $22.0 \pm 1.4$ & $22.6 \pm 3.0$ & $22.4 \pm 1.0$ & $23.2 \pm 1.9$ & $40.1 \pm 6.9$ \\
Commercial ZnO & $22.0 \pm 1.4$ & $22.0 \pm 0.8$ & $22.0 \pm 0.7$ & $24.3 \pm 2.8$ & $37.3 \pm 8.7$ \\
\hline
\end{tabular}

\section{Conclusions}

In this work, a new use of zinc oxide particles from spent alkaline batteries is developed, avoiding environmental and health problems. Thousands of tons of alkaline batteries are recycled across the world each year.

Recycled $\mathrm{ZnO}$ particles present an inner moisture content, which enhances the interaction with epoxy matrix, obtaining composites with enhanced thermal and mechanical properties.

The recycled particles have a specific geometry, shaped as desert roses with an average diameter of $2.5 \mu \mathrm{m}$. These dense ceramic particles suffer sedimentation during the curing treatment of epoxy resin. The experimental parameters that influence the sedimentation phenomenon are studied, such as the low viscosity of non-cured resin, the relative high gel time to form a crosslinked network and the size 
of added particles. If any material can be modified, in principle, the composites with recycled ceramic particles could not be manufactured by conventional processes. For it, a new manufacturing method has been successfully developed using a rotatory mold to avoid the sedimentation. This allows for the manufacturing of homogenous composites which achieve thermomechanical properties enhancements with higher ceramic filler contents than conventional methods. In summary, the composite reinforced with $30 \mathrm{wt} \%$ recycled $\mathrm{ZnO}$ particles presents enhancements in its glass transition temperature $(1.4 \%)$, its stiffness (19.2\%) and hardness (82.3\%). Moreover, this method results in an easily applicable way to optimize any other reinforced polymer networks with positive results, as demonstrated with the epoxy-commercial $\mathrm{ZnO}$ composites.

Author Contributions: Conceptualization, M.C. and S.G.P.; methodology, I.L., G.D.R. and F.A.L.; investigation, I.L., M.C., G.D.R., F.A.L., S.G.P.; writing—original draft preparation, I.L.; writing-review and editing, S.G.P.; S.G.P. and F.A.L.; funding acquisition, S.G.P. All authors have read and agreed to the published version of the manuscript.

Funding: This research was funded by Ministerio de Ciencia e Innovación of Spain Government, project number PID2019-106703RB-I00) and Comunidad de Madrid Government, project number ADITIMAT-CM C2018/NMT-4411.

Acknowledgments: The authors would like to acknowledge the Ministerio de Ciencia e Innovación of Spain Government (PID2019-106703RB-I00) and Comunidad de Madrid Government (ADITIMAT-CM C2018/NMT-4411).

Conflicts of Interest: The authors declare no conflict of interest.

\section{References}

1. Zhang, X.; Shi, F.; Niu, J.; Jiang, Y.; Wang, Z. Superhydrophobic surfaces: From structural control to functional application. J. Mater. Chem. 2008, 18, 621-633. [CrossRef]

2. Peng, W.; Gou, X.; Qin, H.; Zhao, M.; Zhao, X.; Guo, Z. Creation of a multifunctional superhydrophobic coating for composite insulators. Chem. Eng. J. 2018, 352, 774-781. [CrossRef]

3. Han, S.; Yao, T.; Yang, X. Preparation and anti-icing properties of a hydrophobic emulsified asphalt coating. Constr. Build. Mater. 2019, 220, 214-227. [CrossRef]

4. Ammar, S.; Ramesh, K.; Vengadaesvaran, B.; Ramesh, S.; Arof, A.K. Amelioration of anticorrosion and hydrophobic properties of epoxy/PDMS composite coatings containing nano ZnO particles. Prog. Org. Coat. 2016, 92, 54-65. [CrossRef]

5. Ramezanzadeh, B.; Attar, M.M.; Farzam, M. A study on the anticorrosion performance of the epoxy-polyamide nanocomposites containing ZnO nanoparticles. Prog. Org. Coat. 2011, 72, 410-422. [CrossRef]

6. Arribas, C.; Prolongo, M.G.; Sánchez-Cabezudo, M.; Moriche, R.; Prolongo, S.G. Hydrothermal ageing of graphene/carbon nanotubes/epoxy hybrid nanocomposites. Polym. Degrad. Stab. 2019, 170, 109003. [CrossRef]

7. Psarski, M.; Celichowski, G.; Marczak, J.; Gumowski, K.; Sobieraj, G.B. Superhydrophobic dual-sized filler epoxy composite coatings. Surf. Coatings Technol. 2013, 225, 66-74. [CrossRef]

8. Zhang, X.; Si, Y.; Mo, J.; Guo, Z. Robust micro-nanoscale flowerlike ZnO/epoxy resin superhydrophobic coating with rapid healing ability. Chem. Eng. J. 2017, 313, 1152-1159. [CrossRef]

9. Lorwanishpaisarn, N.; Kasemsiri, P.; Srikhao, N.; Jetsrisuparb, K.; Knijnenburg, J.T.N.; Hiziroglu, S.S.; Pongsa, U.; Chindaprasirt, P. Fabrication of durable superhydrophobic epoxy/cashew nut shell liquid based coating containing flower-like zinc oxide for continuous oil/water separation. Surf. Coat. Technol. 2019, 366, 106-113. [CrossRef]

10. Zhou, H.; Chen, R.; Liu, Q.; Liu, J.; Yu, J.; Wang, C.; Zhang, M.; Liu, P.; Wang, J. Fabrication of ZnO/epoxy resin superhydrophobic coating on AZ31 magnesium alloy. Chem. Eng. J. 2019, 368, 261-272. [CrossRef]

11. Wang, N.; Tang, L.; Cai, Y.; Tong, W.; Xiong, D. Scalable superhydrophobic coating with controllable wettability and investigations of its drag reduction. Colloids Surf. Asp. 2018, 555, 290-295. [CrossRef]

12. Sari, M.G.; Vahabi, H.; Gabrion, X.; Laheurte, P.; Zarrintaj, P.; Formela, K.; Saeb, M.R. An attempt to mechanistically explain the viscoelastic behavior of transparent epoxy/starch-modified ZnO nanocomposite coatings. Prog. Org. Coat. 2018, 119, 171-182. [CrossRef] 
13. Ponnamma, D.; Cabibihan, J.; Rajan, M.; Pethaiah, S.S.; Deshmukh, K.; Gogoi, J.P.; Pasha, S.K.K.; Ahamed, M.B.; Krishnegowda, J.; Chandrashekar, B.N.; et al. Synthesis, optimization and applications of ZnO/polymer nanocomposites. Mater. Sci. Eng. C 2019, 98, 1210-1240. [CrossRef] [PubMed]

14. Halder, S.; Prasad, T.; Khan, N.I.; Goyat, M.S.; Chauhan, S.R. Superior mechanical properties of poly vinyl alcohol-assisted ZnO nanoparticle reinforced epoxy composites. Mater. Chem. Phys. 2017, 192, 198-209. [CrossRef]

15. Antunes, P.V.; Ramalho, A.; Carrilho, E.V.P. Mechanical and wear behaviours of nano and microfilled polymeric composite.Effect of filler fraction and size. Mater. Des. 2014, 61, 50-60. [CrossRef]

16. Shi, L.; Hu, J.; Lin, X.; Fang, L.; Wu, F.; Xie, J.; Meng, F. A robust superhydrophobic PPS-PTFE/SiO2 composite coating on AZ31 Mg alloy with excellent wear and corrosion resistance properties. J. Alloys Compd. 2017, 721, 157-163. [CrossRef]

17. Dhoke, S.K.; Khanna, A.S.; Sinha, T.J.M. Effect of nano-ZnO particles on the corrosion behavior of alkyd-based waterborne coatings. Prog. Org. Coat. 2009, 64, 371-382. [CrossRef]

18. Sandhya, P.K.; Sreekala, M.S.; Padmanabhan, M.; Thomas, S. Mechanical and thermal properties of ZnO anchored GO reinforced phenol formaldehyde resin. Diam. Relat. Mater. 2020, 108, 107961. [CrossRef]

19. Ghamsari, M.S.; Alamdari, S.; Razzaghi, D.; Pirlar, M.A. ZnO nanocrystals with narrow-band blue emission. J. Lumin. 2019, 205, 508-518. [CrossRef]

20. Hawkins, S.A.; Yao, H.; Wang, H.; Sue, H.J. Tensile properties and electrical conductivity of epoxy composite thin films containing zinc oxide quantum dots and multi-walled carbon nanotubes. Carbon N. Y. 2017, 115, 18-27. [CrossRef]

21. Kumar, A.M.; Khan, A.; Khan, M.Y.; Suleiman, R.K.; Jose, J.; Dafalla, H. Hierarchical graphitic carbon nitride-ZnO nanocomposite: Viable reinforcement for the improved corrosion resistant behavior of organic coatings. Mater. Chem. Phys. 2020, 251, 122987. [CrossRef]

22. Zabihi, O.; Mostafavi, S.M.; Ravari, F.; Khodabandeh, A.; Hooshafza, A.; Zare, K.; Shahizadeh, M. The effect of zinc oxide nanoparticles on thermo-physical properties of diglycidyl ether of bisphenol A/2,2'-Diamino-1,1'-binaphthalene nanocomposites. Thermochim. Acta 2011, 521, 49-58. [CrossRef]

23. Karasinski, E.N.; da Luz, M.G.; Lepienski, C.M.; Coelho, L.A.F. Nanostructured coating based on epoxy/metal oxides: Kinetic curing and mechanical properties. Thermochim. Acta 2013, 569, 167-176. [CrossRef]

24. Ghaffari, M.; Ehsani, M.; Vandalvand, M.; Avazverdi, E.; Askari, A.; Goudarzi, A. Studying the effect of microand nano-sized $\mathrm{ZnO}$ particles on the curing kinetic of epoxy/polyaminoamide system. Prog. Org. Coat. 2015, 89, 277-283. [CrossRef]

25. Jena, K.K.; Alhassan, S.M.; Arora, N. Facile and rapid synthesis of efficient epoxy-novolac acrylate/ MWCNTs-APTES-ZnO hybrid coating films by UV irradiation: Thermo-mechanical, shape stability, swelling, hydrophobicity and antibacterial properties. Polymer (Guildf) 2019, 179, 121621. [CrossRef]

26. Ma, J.; An, W.; Xu, Q.; Fan, Q.; Wang, Y. Antibacterial casein-based ZnO nanocomposite coatings with improved water resistance crafted via double in situ route. Prog. Org. Coat. 2019, 134, 40-47. [CrossRef]

27. Xu, J.; Song, R.; Dai, Y.; Yang, S.; Li, J.; Wei, R. Characterization of zinc oxide nanoparticles-epoxy resin composite and its antibacterial effects on spoilage bacteria derived from silvery pomfret (Pampus argenteus). Food Packag. Shelf Life 2019, 22, 100418. [CrossRef]

28. Malucelli, G.; Fioravanti, A.; Francioso, L.; de Pascali, C.; Signore, M.A.; Carotta, M.C.C.; Bonanno, A.; Duraccio, D. Preparation and characterization of UV-cured composite films containing ZnO nanostructures: Effect of filler geometric features on piezoelectric response. Prog. Org. Coat. 2017, 109. [CrossRef]

29. Guo, L.; Zhang, Z.; Kang, R.; Chen, Y.; Hou, X.; Wu, Y.; Wang, M.; Wang, B.; Cui, J.; Jiang, N.; et al. Enhanced thermal conductivity of epoxy composites filled with tetrapod-shaped ZnO. RSC Adv. 2018, 8, 12337-12343. [CrossRef]

30. Yuan, F.Y.; Zhang, H.B.; Li, X.; Li, X.Z.; Yu, Z.Z. Synergistic effect of boron nitride flakes and tetrapod-shaped $\mathrm{ZnO}$ whiskers on the thermal conductivity of electrically insulating phenol formaldehyde composites. Compos. Part A Appl. Sci. Manuf. 2013, 53, 137-144. [CrossRef]

31. Jiang, Y.; Sun, R.; Zhang, H.B.; Min, P.; Yang, D.; Yu, Z.Z. Graphene-coated ZnO tetrapod whiskers for thermally and electrically conductive epoxy composites. Compos. Part A Appl. Sci. Manuf. 2017, 94, 104-112. [CrossRef] 
32. Deka, B.K.; Hazarika, A.; Kwon, O.; Kim, D.Y.; Park, Y.B.; Park, H.W. Multifunctional enhancement of woven carbon fiber/ZnO nanotube-based structural supercapacitor and polyester resin-domain solid-polymer electrolytes. Chem. Eng. J. 2017, 325, 672-680. [CrossRef]

33. Yari, H.; Rostami, M. Enhanced weathering performance of epoxy/ZnO nanocomposite coatings via functionalization of $\mathrm{ZnO} U \mathrm{UV}$ blockers with amino and glycidoxy silane coupling agents. Prog. Org. Coat. 2020, 147, 105773. [CrossRef]

34. Xavier, L.H.; Giese, E.C.; Ribeiro-Duthie, A.C.; Lins, F.A.F. Sustainability and the circular economy: A theoretical approach focused on e-waste urban mining. Resour. Policy 2019, 101467. [CrossRef]

35. López, F.A.; Cebriano, T.; García-Díaz, I.; Fernández, P.; Rodríguez, O.; Fernández, A.L. Synthesis and microstructural properties of zinc oxide nanoparticles prepared by selective leaching of zinc from spent alkaline batteries using ammoniacal ammonium carbonate. J. Clean. Prod. 2017, 148, 795-803. [CrossRef]

36. Cebriano, T.; García-Díaz, I.; Fernández, A.L.; Fernández, P.; López, F.A. Synthesis and characterization of $\mathrm{ZnO}$ micro- and nanostructures grown from recovered $\mathrm{ZnO}$ from spent alkaline batteries. J. Environ. Chem. Eng. 2017, 5, 2903-2911. [CrossRef]

37. Song, S.Y.; Park, M.S.; Lee, D.; Lee, J.W.; Yun, J.S. Optimization and characterization of high-viscosity ZrO2 ceramic nanocomposite resins for supportless stereolithography. Mater. Des. 2019, 180, 107960. [CrossRef]

38. Paul, N.; Biggs, S.; Shiels, J.; Hammond, R.B.; Edmondson, M.C.; Maxwell, L.; Harbottle, D.; Hunter, T.N. Influence of shape and surface charge on the sedimentation of spheroidal, cubic and rectangular cuboid particles. Powder Technol. 2017, 322, 75-83. [CrossRef]

39. Nolte, H.; Schilde, C.; Kwade, A. Production of highly loaded nanocomposites by dispersing nanoparticles in Epoxy Resin. Chem. Eng. Technol. 2010, 33, 1447-1455. [CrossRef]

40. González-Campo, A.; Orchard, K.L.; Sato, N.; Shaffer, M.S.P.; Williams, C.K. One-pot, in situ synthesis of $\mathrm{ZnO}-$ carbon nanotube-epoxy resin hybrid nanocomposites. Chem. Commun. 2009, 4034-4036. [CrossRef]

41. Mills, P.; Snabre, P. Settling of a suspension of hard spheres. Europhys. Lett. 1994, 25, 651-656. [CrossRef]

42. Valverde, J.M.; Quintanilla, M.A.S.; Castellanos, A.; Mills, P. The settling of fine cohesive powders. Europhys. Lett. 2001, 54, 329-334. [CrossRef]

43. Mostafaei, A.; Zolriasatein, A. Synthesis and characterization of conducting polyaniline nanocomposites containing ZnO nanorods. Prog. Nat. Sci. Mater. Int. 2012, 22, 273-280. [CrossRef]

44. Ghule, K.; Ghule, A.V.; Chen, B.J.; Ling, Y.C. Preparation and characterization of ZnO nanoparticles coated paper and its antibacterial activity study. Green Chem. 2006, 8, 1034-1041. [CrossRef]

45. Ahmadi, Z. Nanostructured epoxy adhesives: A review. Prog. Org. Coat. 2019, 135, 449-453. [CrossRef] 